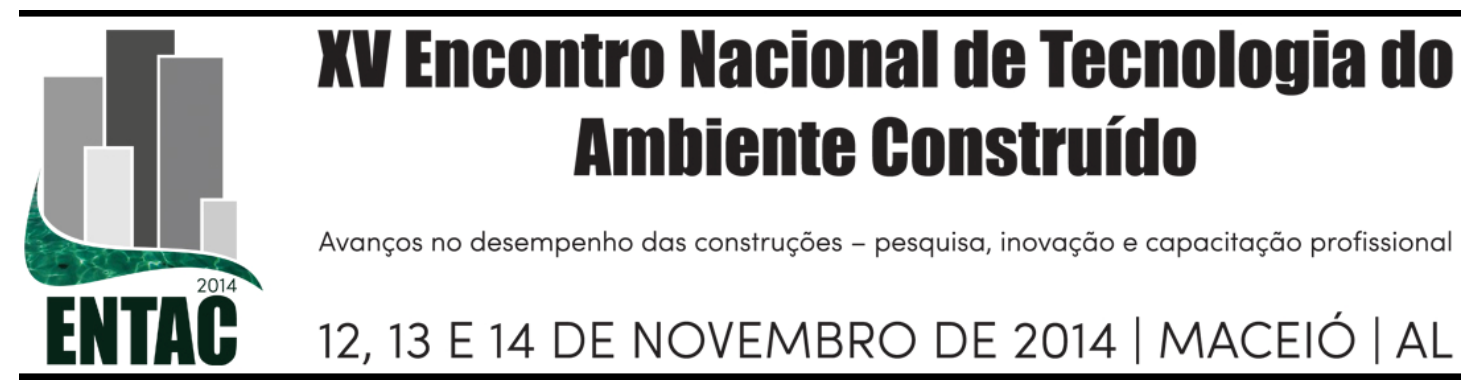

\title{
IMPLANTAÇÃO DA ABNT NBR 15575:2013 EM EMPRESAS INCORPORADORAS E CONSTRUTORAS A PARTIR DE PROCESSOS DE SISTEMAS DE GESTÃO DA QUALIDADE
}

\author{
OTERO, Juliano Araújo (1); SPOSTO, Rosa Maria (2)
}

(1) Universidade de Brasília - UnB PECC, e-mail: juliano.otero@gmail.com

(2) Universidade de Brasília - UnB PECC, e-mail: rmsposto@unb.br

\begin{abstract}
RESUMO
As normas ABNT NBR 15575 estabelecem requisitos para o desempenho de edificações habitacionais com base nas necessidades dos usuários e definem uma série de responsabilidades para diversos agentes atuantes no setor da construção. Apesar das diversas ações realizadas no sentido de informar e sensibilizar tais intervenientes, grande parte das empresas incorporadoras e construtoras aparentemente permanece insegura e desinformada quanto à extensão de suas responsabilidades e às ações que devem ser desenvolvidas para cumprimento destas normas, principalmente em função da complexidade e abrangência dos requisitos envolvidos. Por outro lado, um fato importante que deve contribuir para a aplicação das normas de desempenho é a disseminação em larga escala de sistemas de gestão da qualidade no setor de construção brasileiro, fundamentados na ABNT NBR ISO 9001:2008 e no PBQP-H $\mathrm{SiAC}$, que trazem em si processos voltados para a garantia do atendimento aos requisitos de clientes, propiciando a implementação das exigências de desempenho de modo gradual e consistente, com a priorização de investimentos com base em dados objetivos. Este artigo apresenta uma análise sobre como diferentes processos de um sistema de gestão da qualidade podem contribuir para o atendimento dos requisitos e critérios previstos na ABNT NBR 15575:2013, resultando em uma lista de ações relacionadas a controle de projetos, qualificação e contratação de projetistas, laboratórios e fornecedores de materiais e componentes, controle de execução de serviços, avaliação da satisfação de clientes e monitoramento de edifícios pós-ocupação.
\end{abstract}

Palavras-chave: Edificações Habitacionais, Normas de Desempenho, Sistemas de Gestão da Qualidade.

\begin{abstract}
The Brazilian standard ABNT NBR 15575, published in 2013, establishes requirements for residential buildings performance based on user needs and defines responsibilities to various agents in the construction sector. Despite various actions undertaken to inform and sensitize stakeholders, many construction companies apparently remains insecure and uninformed about the extent of their responsibilities and actions to be developed to meet these standards, mainly due to the complexity and extension of the requirements involved. An important fact that can contribute to the implementation of performance standards is the large-scale quality management systems in the Brazilian construction sector, based on ISO 9001:2008 and the Brazilian Program of Quality and Productivity at Habitat $P B Q P-H$ SiAC, ensuring compliance with costumers requirements, allowing the implementation of performance requirements in a gradual and consistent process in which investments can be prioritized based on objective data. This paper presents an analysis of how different processes of a quality management system can contribute to meeting the requirements and criteria set out in ABNT NBR 15575:2013, resulting in a list of actions related to project control, qualification and hiring designers, laboratories and suppliers of materials and components, service execution control, customer satisfaction assessment and post-occupational building monitoring.
\end{abstract}

Keywords: Residential Buildings, Building Performance Standards, Quality Management Systems. 


\section{INTRODUÇÃO}

A série de normas ABNT NBR 15575 - Edificações Habitacionais - Desempenho, em sua última versão, entrou em vigor em julho de 2013, estabelecendo requisitos e critérios de desempenho para edificações habitacionais, independentemente da forma do edifício e dos sistemas construtivos e materiais que os constituem, baseados nas necessidades de seus usuários. (CBIC, 2013)

A efetiva aplicação do conceito de desempenho na construção depende de vários fatores e, no Brasil, um aspecto oportuno a ser discutido trata dos mecanismos para implementação da ABNT NBR 15575, uma vez que são envolvidos aspectos extremamente abrangentes e complexos, englobando diversas áreas de conhecimento tecnicamente especializadas e requer a qualificação e o engajamento de diversos profissionais e da cadeia fornecedora como um todo, o incentivo e a fiscalização do poder público, o desenvolvimento de pesquisas e a conscientização e exigência por parte dos consumidores e da sociedade em geral (SILVA et al., 2011).

Apesar das diversas ações realizadas por sindicatos e instituições de ensino e pesquisa no sentido de informar e sensibilizar os agentes relacionados à ABNT NBR 15575, grande parte das empresas incorporadoras e construtoras aparentemente permanece insegura e desinformada quanto à extensão de suas responsabilidades e às ações que devem ser desenvolvidas para cumprimento destas normas.

Descrito de modo sintético, as normas ABNT NBR 15575:2013 geram uma série de atribuições para empresas incorporadoras e construtoras, estabelecendo que estas se tornem aptas a identificar de modo claro as condições físicas do ambiente que envolve a obra e os requisitos dos usuários com relação ao desempenho da edificação, gerenciar a contratação de projetistas, laboratórios e fornecedores de materiais e componentes, controlar e manter evidências do cumprimento dos requisitos de desempenho (projetos, materiais e execução de serviços de modo adequado) e a preparação de manuais de uso, operação e manutenção.

No caso brasileiro, uma situação que deve contribuir para a aplicação das normas de desempenho é a disseminação em larga escala de sistemas de gestão da qualidade no setor de construção, fundamentados na norma ABNT NBR ISO 9001:2008 (ABNT, 2008) e no Sistema de Avaliação da Conformidade de Empresas de Serviços e Obras da Construção Civil do Programa Brasileiro da Qualidade e Produtividade no Habitat PBQP-H SiAC (BRASIL, 2012), os quais trazem em si toda uma série de processos voltados para a garantia do atendimento a requisitos de clientes, propiciando a implementação da garantia do desempenho dos edifícios de maneira gradual e consistente, na qual investimentos podem ser priorizados com base em dados objetivos. Segundo dados disponíveis no website do programa (BRASIL, 2014), atualmente há cerca de 1850 empresas certificadas no PBQP-H SiAC.

Este artigo se desenvolve a partir de uma discussão do relacionamento existente entre o conteúdo da norma ABNT NBR 15575:2013, com seus reflexos nas obras e sobre as atribuições de empresas incorporadoras e construtoras, e os processos definidos pela NBR ISO 9001:2008 e pelo PBQP-H SiAC para sistemas de gestão da qualidade. Com base em tal discussão, estrutura-se uma lista procedimentos e ações que podem ser incorporadas nos sistemas de gestão da qualidade destas empresas a fim de garantir o atendimento das normas de desempenho.

O trabalho ora apresentado se insere em pesquisa realizada no âmbito do Programa de Pós-Graduação em Estruturas e Construção Civil da Universidade de Brasília - UnB PECC sobre o uso de ferramentas de análise de risco e tomada de decisão na 
implantação de processos para atendimento à ABNT NBR 15575:2013 por empresas incorporadoras e construtoras.

\section{NORMAS DE DESEMPENHO ABNT NBR 15575:2013}

As normas da série ABNT NBR 15575:2013 foram publicadas como um conjunto normativo que compreende seis partes, sendo a primeira relativa a requisitos gerais e as demais referentes a requisitos para sistemas estruturais, sistemas de pisos, sistemas de vedações verticais internas e externas, sistemas de coberturas e sistemas hidrossanitários, respectivamente. Diversos outros elementos e sistemas construtivos não foram diretamente considerados no atual estágio da norma. (CBIC, 2013)

As exigências dos usuários, objeto das normas de desempenho, devem ser entendidas como necessidades a serem satisfeitas pelo edifício, a fim de cumprir suas funções. No caso de edifícios de uso habitacional, tais exigências correspondem às exigências humanas de caráter fisiológico, psicológico, sociológico e econômico, sendo, portanto, condições necessárias à segurança e saúde do homem, ao seu conforto e à satisfação de suas preocupações econômicas, assim como às necessidades do edifício conservar suas características ao longo do tempo (MITIDIERI FILHO; HELENE, 1998).

A ABNT NBR 15575:2013 define os seguintes aspectos como exigências do usuário de edifícios habitacionais: segurança estrutural, segurança contra o fogo, segurança no uso e na operação, estanqueidade, desempenho térmico, desempenho acústico, desempenho lumínico, saúde, higiene e qualidade do ar, funcionalidade e acessibilidade, conforto tátil e antropodinâmico, durabilidade, manutenibilidade e impacto ambiental. $\mathrm{O}$ atendimento aos requisitos e critérios relativos a tais aspectos pode ser questionado por usuários consumidores a qualquer momento, caso haja dúvida ou discussão sobre a qualidade da construção e o cumprimento de obrigações pelos agentes intervenientes, e sua comprovação pode ser necessária. (CBIC, 2013)

A avaliação do desempenho de edificações segundo estabelecido na ABNT NBR 15575:2013 exige o domínio de uma ampla base de conhecimentos científicos sobre cada aspecto funcional da obra, sobre materiais e técnicas de construção, bem como sobre diferentes requisitos de usuários nas mais diversas condições de uso. Os métodos de avaliação estabelecidos consideram a realização de ensaios laboratoriais, ensaios de tipo, ensaios em campo, inspeções em protótipos ou em campo, simulações e análise de projetos. (ABNT, 2013)

\subsection{Responsabilidades de empresas incorporadoras e construtoras}

As normas ABNT NBR 15575:2013 estabelecem uma série de responsabilidades específicas para agentes envolvidos no processo de desenvolvimento, produção e uso de edificações habitacionais, conforme citadas na Quadro 1.

Além destas atribuições, há aquelas decorrentes da própria natureza das funções destes agentes perante a ABNT NBR 15575:2013: para projetistas, a elaboração de projetos que atendam às premissas de projeto e às normas técnicas previstas como critério de desempenho; para fornecedores de materiais e componentes, a disponibilização de produtos que respeitem as características de desempenho informadas; e para construtores, execução da obra respeitando integralmente os projetos definidos. 
Quadro 1 - Incumbências técnicas estabelecidas pela ABNT NBR 15575 para os intervenientes envolvidos no processo construtivo (ABNT, 2013)

\begin{tabular}{|c|c|}
\hline Agente Interveniente & Responsabilidades Previstas \\
\hline $\begin{array}{c}\text { Incorporadores e } \\
\text { Construtores }\end{array}$ & $\begin{array}{l}\text { - Salvo convenção escrita, cabe ao incorporador, junto com os projetistas } \\
\text { envolvidos, a identificação dos riscos previsíveis na época do projeto, } \\
\text { devendo o incorporador, neste caso, providenciar os estudos técnicos } \\
\text { requeridos e alimentar os diferentes projetistas com tais informações; } \\
\text { - Ao construtor ou incorporador cabe elaborar o manual de operação, uso } \\
\text { e manutenção da edificação, ou documento similar, que deve ser entregue } \\
\text { ao proprietário da unidade quando da entrega do edifício para uso, } \\
\text { incluindo o manual de áreas comuns, a ser entregue ao condomínio. }\end{array}$ \\
\hline Projetistas & $\begin{array}{l}\text { - Especificar materiais, produtos e processos que atendam aos } \\
\text { desempenhos mínimos estabelecidos na ABNT NBR 15575:2013 com } \\
\text { base em normas prescritivas disponíveis e no desempenho declarado pelos } \\
\text { fabricantes dos produtos a serem empregados; } \\
\text { - Solicitar informações ao fabricante para balizar as decisões de } \\
\text { especificação quando as normas específicas de produtos não caracterizem } \\
\text { desempenho ou quando não existirem normas específicas; } \\
\text { - Estabelecer a vida útil projetada de cada sistema que compõe a } \\
\text { edificação habitacional e apresentar seus valores em projeto quando estes } \\
\text { forem maiores que os mínimos estabelecidos na ABNT NBR 15575:2013. }\end{array}$ \\
\hline $\begin{array}{l}\text { Fornecedores de } \\
\text { Insumos, Materiais, } \\
\text { Componentes e } \\
\text { Sistemas }\end{array}$ & $\begin{array}{l}\text { - Caracterizar o desempenho dos produtos que fornece de acordo com os } \\
\text { critérios definidos na ABNT NBR 15575:2013; } \\
\text { - Convém que fabricantes de produtos sem normas brasileiras } \\
\text { específicas ou que não tenham seu desempenho caracterizado forneçam } \\
\text { resultados comprobatórios do desempenho de seus produtos. }\end{array}$ \\
\hline Usuários & $\begin{array}{l}\text { - Realizar a manutenção do edifício, conforme a norma ABNT NBR } \\
5674 \text { - Manutenção de edificações - Procedimentos e o manual de } \\
\text { operação, uso e manutenção apresentado pelo incorporador ou construtor. }\end{array}$ \\
\hline
\end{tabular}

Deve ser ressaltado que ao se apresentarem como contratantes de projetistas e de fornecedores de materiais e componentes, as empresas incorporadoras e construtoras também acabam por trazer para si a responsabilidade de controlar os projetos e produtos adquiridos.

A implementação de processos para atendimento às normas ABNT NBR 15575:2013 representa um esforço significativo por parte dos diversos agentes envolvidos, principalmente em função da complexidade e abrangência dos requisitos definidos, seja pelo volume de informações e pela multiplicidade das áreas tecnicamente especializadas envolvidas, seja pela novidade representada por alguns dos aspectos abordados e dos métodos de avaliação estabelecidos. Quanto a empresas incorporadoras e construtoras, torna-se quase indispensável a definição de prioridades, dentro de um processo de longo prazo, para incorporação de rotinas para atendimento à norma. Neste sentido, os sistemas de gestão da qualidade permitem o planejamento, implantação e controle de várias destas rotinas ao trazer para seu foco as necessidades de desempenho definidas na ABNT NBR 15575:2013.

\section{EXIGÊNCIAS DE DESEMPENHO E GESTÃO DA QUALIDADE}

Segundo a ABNT NBR ISO 9000:2005, a implementação de um sistema de gestão da qualidade incentiva as organizações a analisar os requisitos do cliente, definir os processos que contribuem para a obtenção de um produto adequado e manter estes processos sob controle, fornecendo ainda uma estrutura para melhoria contínua com o objetivo de aumentar a satisfação do cliente. (ABNT, 2005) 
Sistemas de gestão da qualidade são compostos por estruturas organizacionais, responsabilidades, procedimentos, atividades e recursos que, em conjunto, têm por objetivo demonstrar a capacidade da empresa de fornecer produtos e serviços que atendam aos requisitos do cliente (BRASIL, 2012).

Os conceitos de qualidade e desempenho são muito próximos entre si. Souza et al. (1994) aponta que o desempenho de uma edificação, como seu comportamento em uso no que se relaciona ao cumprimento de funções relativas a segurança, habitabilidade, durabilidade e economia, representa em larga escala o que seria a qualidade da obra, entendida como "adequação ao uso" ou satisfação das necessidades do cliente.

Com isso, a abordagem do conceito de desempenho dentro do sistema de gestão da qualidade de empresas incorporadoras e construtoras pode ser realizada de um modo natural. A seguir são apresentados requisitos definidos na ABNT NBR ISO 9001:2008 e no PBQP-H SiAC que se relacionam com a implementação dos requisitos, critérios e métodos de avaliação apontadas na ABNT NBR 15575:2013.

\subsection{Identificação e análise crítica de requisitos do cliente}

A ABNT NBR 9001:2008 e o PBQP-H SiAC estabelecem que a organização deve identificar e analisar criticamente o requisitos do cliente, que englobam aqueles diretamente especificados, aqueles não especificados pelo cliente mas necessários para o uso do produto, obrigações legais e regulamentares, assim como requisitos adicionais definidos pela própria empresa, a fim de garantir sua capacidade de atendê-los (ABNT, 2008; BRASIL, 2013).

Para todos os requisitos e critérios incluídos na ABNT NBR 15575:2013, foram estabelecidos patamares mínimos de desempenho, que devem ser obrigatoriamente atingidos pelos diferentes elementos e sistemas da construção, independente da classe do produto e do custo do edifício. Para alguns critérios são indicados outros dois níveis de desempenho, intermediário e superior, de caráter facultativo (CBIC, 2013).

As normas técnicas, inclusive a ABNT NBR 15575:2013, não possuam caráter compulsório, no entanto adquirem força por meio de leis e regulamentos que as apontam como referência. Neste sentido, o Código de Defesa do Consumidor impede a colocação no mercado de qualquer produto ou serviço em desacordo com as normas expedidas pelos órgãos oficiais competentes e pela Associação Brasileira de Normas Técnicas - ABNT, sendo tal prática considerada abusiva (BRASIL, 1990). Desta forma, no âmbito de seus sistemas de gestão da qualidade, as empresas incorporadoras e construtoras devem assumir os requisitos e critérios mínimos apontados na ABNT NBR 15575:2013 como requisitos do cliente.

Quanto à análise crítica destes requisitos, deve ser considerado que, dentre as exigências do usuário, há aquelas de caráter absoluto, como o caso da segurança estrutural, e outras de caráter relativo, relacionadas a conforto e durabilidade (MITIDIERI FILHO; HELENE, 1998), e que o fato de não se considerar explicitamente os aspectos de desempenho durante a elaboração de projetos não significa, necessariamente, que o edifício resultante não atenda a determinados critérios de desempenho (OLIVEIRA; MITIDIERI FILHO, 2012).

Em função da complexidade e da extensão dos aspectos envolvidos, a análise crítica dos requisitos deve fundamentar-se em processos de análise de riscos, baseados no histórico da empresa de reclamações de clientes, no monitoramento de obras anteriormente entregues e na bibliografia disponível, a fim de garantir sua capacidade de atender aos requisitos de desempenho. 


\subsection{Controle de projetos}

A ABNT NBR 9001:2008 e o PBQP-H SiAC estabelecem que a organização deve definir e analisar as informações de entrada do processo de projeto, verificar e analisar criticamente as informações contidas em projeto, inclusive garantindo a compatibilização entre diferentes especialidades técnicas, e validar os resultados dos projetos de modo a assegurar que o produto resultante é capaz de atender aos requisitos para uso especificados ou pretendidos (ABNT, 2008; BRASIL, 2013).

Oliveira; Mitidieri Filho (2012) aponta que, no mercado brasileiro, o desenvolvimento dos projetos normalmente prioriza decisões sobre arquitetura e seleção de tecnologias para, posteriormente e nem sempre, considerar $\mathrm{o}$ atendimento a exigências de desempenho. Tal situação deve ser alterada em função da entrada em vigor da ABNT NBR 15575:2013, com projetos de edifícios passando a ser elaborados com enfoque nos requisitos de desempenho, considerados desde a fase de concepção.

Segundo esta norma, como parte das informações a serem repassadas a projetistas, a identificação dos riscos previsíveis na época do projeto faz parte das responsabilidades do incorporador, que deve, quando for o caso, providenciar os estudos técnicos requeridos e alimentar os diferentes projetistas com os resultados. (ABNT, 2013)

Também devem ser estabelecidos critérios claros para seleção, qualificação e contratação dos projetistas, incluindo informações sobre a competência destes e requisitos contratuais relativos às exigências de desempenho. Deve ser considerada em programas de necessidade e contratos a necessidade de atendimento às normas técnicas específicas. Além disso, a verificação e análise crítica de projetos devem incluir os requisitos de desempenho pretendidos para o edifício, sendo a contratação de especialistas para análise dos projetos frente às normas técnicas pertinentes uma opção importante. Ao mesmo tempo, podem ser realizados ensaios em protótipos, análise de obras similares e simulações eletrônicas como validação de projetos como atividades de validação de projetos.

\subsection{Aquisição de materiais, componentes e sistemas construtivos}

Souza et al. (1994) cita que a existência de especificações claras, com requisitos definidos e documentados, permite uma comunicação efetiva ente compradores e fornecedores, reduzindo eventuais desentendimentos. É importante que os documentos de compra de materiais e componentes especifiquem os critérios de desempenho requeridos, refletindo as especificações de projeto e normas técnicas aplicáveis.

Ao mesmo tempo, a ABNT NBR 9001:2008 e o PBQP-H SiAC estabelecem que a organização deve assegurar que o produto adquirido atende aos requisitos especificados (ABNT, 2008; BRASIL, 2013). Neste sentido, os procedimentos de inspeção de materiais devem incluir aspectos de desempenho, incluindo a verificação de selos de conformidade e ensaios de caracterização do produto.

\subsection{Controle da execução de serviços em obra}

A execução da obra deve respeitar integralmente os projetos definidos. Neste sentido, é importante que os procedimentos de execução e inspeção de serviços reflitam aspectos de desempenho dos edifícios e a garantia do cumprimento dos projetos. Em função das responsabilidades atribuídas a projetistas, eventuais necessidades de modificação identificação durante a execução da obra devem ser comunicadas de modo adequado, com a revisão do projeto com a concordância do projetista envolvido para geração do projeto as built. 


\subsection{Manual de uso, operação e manutenção}

O PBQP-H SiAC define que, no caso de obras de edificações, o processo de entrega da obra deve incluir o fornecimento ao cliente de manual de uso, operação e manutenção, contendo as principais informações sobre condições de utilização das instalações e equipamentos bem como orientações para a operação e manutenção da obra ao longo da sua vida útil. (BRASIL, 2012)

Cabe à empresa incorporadora ou construtora a elaboração deste manual, atendendo à ABNT NBR 14037 - Manual de operação, uso e manutenção das edificações Conteúdo e recomendações para elaboração e apresentação. Quando for o caso, este manual deve se desdobrar em um manual de áreas comuns, a ser entregue ao condomínio. (ABNT, 2013)

A ABNT NBR 15575:2013 (ABNT, 2013) estabelece que o manual de uso, operação e manutenção deve incluir, entre outras, as seguintes informações: programas de manutenção corretiva e preventiva, incluindo periodicidade, critérios de realização e formas de registro; prazos de garantia estabelecidos para cada sistema que compõe a edificação; recomendações gerais para prevenção de falhas e acidentes decorrentes de uso inadequado do edifício; cuidados necessários para o uso correto do edifício, respeitando todos os aspectos previstos em projeto. Trata-se de um documento essencial no que se refere à vida útil do edifício, sendo necessário que o manual de uso, operação e manutenção seja o mais claro e completo possível.

\subsection{Avaliação da satisfação de clientes e monitoramento de obra}

Pesquisas de avaliação pós-ocupação podem gerar informações para a melhoria do ambiente construído, com a possibilidade da identificação de problemas a ser evitados. Diferentes métodos de avaliação pós-ocupação incluem não só avaliações comportamentais, mas também avaliações físicas. A avaliação do usuário da edificação identifica padrões de uso e satisfação com o ambiente construído, enquanto avaliações técnicas geram informações objetivas. (KOWALTOWSKI et al., 2006)

A ABNT NBR 9001:2008 e o PBQP-H SiAC estabelecem que deve ser avaliada a satisfação de clientes, quanto à percepção do atendimento a seus requisitos. Também estabelecem que processos de assistência técnica devem ser controlados, voltados para o atendimento a reclamações de clientes (ABNT, 2008; BRASIL, 2013). Como parte dos serviços de assistência técnica pós-entrega, a inspeção predial se apresenta como ferramenta útil para avaliação das condições de conservação das edificações (ABNT, 2013). Estes processos permitem a identificação de informações sobre o desempenho do edifício e sobre padrões de uso e manutenção adotados.

\subsection{Documentação de processos}

A norma ABNT NBR ISO 9000:2005 cita que a extensão da documentação necessária para o sistema de gestão da qualidade é definida pela própria organização, em função, entre outros aspectos, da necessidade de demonstração do atendimento aos requisitos envolvidos e do valor agregado ao próprio sistema por meio da caracterização e rastreabilidade dos processos realizados e da disponibilização de evidências de seus resultados (ABNT, 2005).

Tendo em vista eventuais discussões sobre a qualidade da obra e o cumprimento das responsabilidades dos intervenientes, torna-se relevante que os documentos e registros gerados no sistema de gestão da qualidade possam prover uma descrição efetiva dos procedimentos técnicos e administrativos realizados e dos resultados alcançados. 


\subsection{Controle de registros}

Segundo CBIC (2013), a comprovação do atendimento à ABNT NBR 15575:2013 poderá ser necessária, a qualquer momento futuro, em caso de dúvida ou discussão sobre a qualidade da construção e o cumprimento de obrigações por parte dos agentes intervenientes, seja no tocante aos projetos, seja quanto à qualidade de execução da construção, sendo importante a manutenção em arquivo, durante os prazos de vida útil, dos projetos, contratos, atas de decisões e demais documentos referentes à obra.

\section{MODIFICAÇÕES PROPOSTAS PARA SISTEMAS DA QUALIDADE}

O Quadro 2 apresenta uma série de procedimentos e ações que podem ser realizados por empresas incorporadoras e construtoras com o objetivo de atender as normas de desempenho ABNT NBR 15575:2013.

\section{Quadro 2 - Procedimentos propostos para sistemas de gestão da qualidade visando o atendimento da ABNT NBR 15575:2013 por incorporadoras e construtoras}

\begin{tabular}{|c|c|}
\hline Processo Correlato & Procedimentos Propostos \\
\hline $\begin{array}{l}\text { Identificação e análise } \\
\text { crítica de requisitos do } \\
\text { cliente }\end{array}$ & $\begin{array}{l}\text { - Inclusão de requisitos mínimos de desempenho da ABNT NBR } \\
\text { 15575:2013 como requisitos do cliente e avaliação das oportunidades } \\
\text { relacionadas à adoção dos níveis intermediários e superiores; } \\
\text { - Realização de análises de risco baseadas no histórico de reclamações de } \\
\text { clientes, falhas e níveis de desempenho de obras anteriores e revisão } \\
\text { bibliográfica sobre métodos construtivos a serem adotados visando garantir a } \\
\text { capacidade de atender aos requisitos de desempenho. }\end{array}$ \\
\hline Controle de projetos & $\begin{array}{l}\text { - Qualificação de projetistas e analistas com base em sua competência na } \\
\text { elaboração de projetos adequados à ABNT NBR 15575:2013; } \\
\text { - Identificação dos requisitos de desempenho definidos para a obra como } \\
\text { entradas de projeto, incluindo normas técnicas que devem ser atendidas e } \\
\text { situações de risco que devem ser consideradas; } \\
\text { - Definição de rotinas para identificação dos riscos previsíveis para o } \\
\text { ambiente no qual a obra deverá ser construída, de modo a caracterizar a } \\
\text { necessidade de estudos técnicos relacionados a tais riscos e gerar informações } \\
\text { para os projetistas envolvidos; } \\
\text { - Inclusão de aspectos relacionados ao desempenho de edificações durante } \\
\text { a especificação de materiais e soluções de projeto e entre as rotinas de } \\
\text { verificação, análise crítica e validação de projetos, inclusive a verificação } \\
\text { específica do cumprimento de normas técnicas aplicáveis. }\end{array}$ \\
\hline $\begin{array}{l}\text { Controle da execução de } \\
\text { serviços em obra }\end{array}$ & $\begin{array}{l}\text { - Desenvolvimento de procedimentos de execução e inspeção de serviços } \\
\text { no sentido de abranger aspectos de desempenho dos edifícios, garantia do } \\
\text { cumprimento dos projetos envolvidos e clareza na caracterização das rotinas } \\
\text { implementadas e dos resultados alcançados; } \\
\text { - Controle adequado de revisões de projeto frente a modificações realizadas } \\
\text { durante a execução da obra, incluindo projetos as built. }\end{array}$ \\
\hline $\begin{array}{c}\text { Avaliação da satisfação de } \\
\text { clientes }\end{array}$ & $\begin{array}{l}\text { - Inclusão de informações sobre aspectos de desempenho do edifício e } \\
\text { sobre padrões de uso, operação e manutenção adotados em ferramentas de } \\
\text { avaliação da satisfação de clientes. }\end{array}$ \\
\hline $\begin{array}{l}\text { Aquisição de materiais, } \\
\text { componentes e sistemas } \\
\text { construtivos }\end{array}$ & $\begin{array}{l}\text { - Inclusão de normas técnicas e requisitos específicos de desempenho em } \\
\text { documentos de compra de materiais e componentes e contratos; } \\
\text { - Inclusão de aspectos relacionados ao desempenho nos procedimentos de } \\
\text { inspeção de materiais, inclusive com solicitação de certificados de ensaio } \\
\text { relativos às características do produto e de conformidade com normas } \\
\text { técnicas. }\end{array}$ \\
\hline
\end{tabular}




\begin{tabular}{|c|c|}
\hline Processo Correlato & Procedimentos Propostos \\
\hline $\begin{array}{l}\text { Contratação de } \\
\text { laboratórios }\end{array}$ & $\begin{array}{l}\text { - Seleção de laboratórios com base em sua competência na realização dos } \\
\text { ensaios previstos na ABNT NBR 15575:2013 e especificação clara dos } \\
\text { métodos e critérios a serem utilizados nos contratos estabelecidos; } \\
\text { - Manutenção de registros de calibração dos equipamentos de medição e } \\
\text { monitoramento utilizados nos ensaios realizados. }\end{array}$ \\
\hline $\begin{array}{c}\text { Inspeção e monitoramento } \\
\text { do produto }\end{array}$ & $\begin{array}{l}\text { - Realização de inspeções prediais pós-entrega, inserido na assistência } \\
\text { técnica, a fim de levantar informações sobre o desempenho do edifício e os } \\
\text { padrões de uso, operação e manutenção adotados pelos usuários; } \\
\text { - Uso de informações sobre reclamações de clientes dentro de processos de } \\
\text { análise de risco, a fim de estabelecer prioridades em atividades voltadas para } \\
\text { a garantia do desempenho de edifícios. }\end{array}$ \\
\hline $\begin{array}{c}\text { Manual de uso, operação } \\
\text { e manutenção }\end{array}$ & $\begin{array}{l}\text { - Inclusão de todas as informações exigidas pela ABNT NBR 15575:2013 } \\
\text { como parte integrante dos manuais de uso, operação e manutenção de obras; } \\
\text { - Adequação dos manuais da empresa à norma ABNT NBR 14037 - } \\
\text { Manual de operação, uso e manutenção das edificações - Conteúdo e } \\
\text { recomendações para elaboração e apresentação; } \\
\text { - Melhoria na elaboração do manual de uso, operação e manutenção quanto } \\
\text { a sua clareza e completude, de modo a minimizar eventuais questionamentos } \\
\text { sobre a disponibilidade de informações adequadas. }\end{array}$ \\
\hline $\begin{array}{l}\text { Documentação de } \\
\text { procedimentos }\end{array}$ & $\begin{array}{l}\text { - Melhoria dos documentos elaborados no âmbito do sistema de gestão da } \\
\text { qualidade no sentido de torná-los mais efetivos como evidências para } \\
\text { terceiros das características dos procedimentos implementados; } \\
\text { - Manutenção em longo prazo dos documentos estabelecidos, mesmo após } \\
\text { seu obsoletismo, e identificação clara do período de sua utilização, de modo a } \\
\text { permitir a caracterização do momento de aplicacação de cada procedimento. }\end{array}$ \\
\hline Controle de registros & $\begin{array}{l}\text { - Melhoria de formulários e registros no sentido de torná-los mais efetivos } \\
\text { como evidências para terceiros das características dos procedimentos } \\
\text { realizados e dos resultados estabelecidos; } \\
\text { - Garantia da disponibilidade de registros relevantes (laudos de ensaio de } \\
\text { materiais, componentes e sistemas construtivos, mapas de rastreabilidade, } \\
\text { certificados de calibração de equipamentos, registros de inspeção de serviços, } \\
\text { entre outros) por prazos equivalentes às vidas úteis de projeto relativas aos } \\
\text { elementos e sistemas correlatos. }\end{array}$ \\
\hline
\end{tabular}

Todas estas ações devem ser planejadas segundo prioridades definidas a partir da análise dos riscos relacionados a cada aspecto de desempenho, permitindo que as empresas incorporadoras e construtoras atuem de modo gradual e consistente na busca da garantia do desempenho de suas obras.

\section{CONSIDERAÇÕES FINAIS}

Como descrito, as empresas incorporadoras e construtoras que possuem sistemas de gestão da qualidade implantados têm a sua disposição diversos processos que podem auxiliar a garantia do desempenho de seus edifícios, com o atendimento dos requisitos e critérios definidos na ABNT NBR 15575:2013.

Além disso, o sistema de gestão da qualidade propicia a geração de uma série de registros que podem ser utilizados como evidências. Um fator fundamental para a garantia da credibilidade destas evidências é a credibilidade do próprio sistema nacional de certificação e, assim, torna-se fundamental todo o esforço empreendido pelo Inmetro, pelo Ministério das Cidades e pelos organismos certificadores, entre outras organizações, para divulgação da importância e utilidade da certificação dos sistemas de gestão da qualidade. 
Também deve ser citado que uma contribuição extremamente importante para a disseminação da ABNT NBR 15575:2013 seria a inclusão de requisitos específicos de desempenho nos documentos que fundamentam o PBQP-H SiAC, dentro de um movimento gradual e evolutivo, segundo princípios deste programa, mas assertivo no propósito de garantir a melhoria da qualidade dos edifícios brasileiros.

\section{REFERÊNCIAS}

ASSOCIAÇÃO BRASILEIRA DE NORMAS TÉCNICAS (ABNT). ABNT NBR ISO 9000 Sistemas de gestão da qualidade - Fundamentos e vocabulário. Rio de Janeiro, 2005.

2008.

. ABNT NBR ISO 9001 - Sistemas de gestão da qualidade - Requisitos. Rio de Janeiro,

Edificações habitacionais: desempenho (coletânea eletrônica). Rio de Janeiro, 2013.

Disponível em: <www.abntcatalogo.com.br>. Acesso em: 4 fev. 2014.

BRASIL. Lei $\mathbf{n}^{0} \mathbf{8 0 7 8}$, de 11 de setembro de 1990. Dispões sobre a proteção do consumidor e dá outras providências. Disponível em: < www.planalto.gov.br/ccivil_03/leis/18078.htm>.

Acesso em: 7 fev. 2014.

BRASIL, Ministério das Cidades. PBQP-HABITAT - Sistema de Avaliação da

Conformidade de Empresas de Serviços e Obras da Construção Civil - SiAC. Brasília, 2012.

PBQP-H - Programa Brasileiro da Qualidade e Produtividade no Habitat (sítio

eletrônico). Disponível em: <www.cidades.gov.br/pbqp-h>. Acesso em: 10 jan. 2014.

CÂMARA BRASILEIRA DA INDÚSTRIA DA CONSTRUÇÃO (CBIC). Desempenho de edificações habitacionais: guia orientativo para atendimento à norma ABNT NBR 15575/2013. Fortaleza, Gadioli Cipolla Comunicação, 2013.

KOWALTOWSKI, D. C. C. K.; CELANI, M. G. C.; MOREIRA, D. C.; PINA, S. A. M. G.; RUSCHEL, R. C.; SILVA, V. G.; LABAKI, L. C.; PETRECHE, J. R. D. Reflexão sobre metodologias de projeto arquitetônico. Ambiente Construído, Porto Alegre: ANTAC, v. 6, n. 2, p. 07-19, abr./jun. 2006.

MITIDIERI FILHO, C. V.; HELENE, P. R. L. Avaliação de desempenho de componentes e elementos construtivos inovadores destinados a habitações: proposições específicas à avaliação do desempenho estrutural, Boletim Técnico BT/PCC/208. São Paulo: EPUSP, 1998.

OLIVEIRA, L. A.; MITIDIERI FILHO, C. V. O projeto de edifícios habitacionais considerando a norma brasileira de desempenho: análise aplicada para vedações verticais. Gestão e

Tecnologia de Projetos, v. 7, n. 1, p. 90-100, mai. 2012.

SILVA, A. T.; KERN, A. P.; KAZMIERCZAK, C. S.; GONZÁLEZ, M. A. S.; CASTRO, R. Comparação entre os processos de implantação do Código Técnico das Edificações na Espanha e NBR 15.575/2008 - Desempenho no Brasil. In: VI ENCONTRO NACIONAL E IV ENCONTRO LATINO-AMERICANO SOBRE EDIFICAÇÕES E COMUNIDADES SUSTENTÁVEIS. Vitória, 2011. Anais...

SOUZA, R.; MEKBEKIAN, G.; SILVA, M. A. C.; LEITÃO, A. C. M. T.; SANTOS, M. M. Sistema de gestão da qualidade para empresas construtoras. São Paulo: CTE - Centro de Tecnologia de Edificações, Sebrae-SP, Sinduscon-SP, 1994. 